\title{
Prevention of concrete structures from collapsing
}

\author{
R. Cechmanek ${ }^{1}$, B. Nespor ${ }^{1}$, M. Drdlova ${ }^{1}$, P. Steffan ${ }^{2}$ and L. Machan ${ }^{2}$ \\ ${ }^{1}$ Research Institute for Building Materials, Department of Applied Research and Development, Brno, Czech Republic \\ ${ }^{2}$ Brno University of Technology, Faculty of Electrical Engineering and Communication, Brno, Czech Republic
}

\begin{abstract}
At the end of the $20^{\text {th }}$ century requirements on using electrical properties of building materials emerged for application in heating of trafficable surfaces, grounding of electrostatic charges in floors, shielding of electro-magnetic fields and diagnosis of concrete structure state in the course of time. For this reason, it was necessary to design special fibre-cement elements able to transfer any mechanical impulse to an electricallymeasured signal detected as a change in electrical resistance with computer outputs. Regarding previous research studies, it was concluded that special fibre-cement composites are able to conduct electric current under specific conditions. This property is ensured by using of various kinds of carbon materials. Though carbon fibres are less conductive than metal fibres, composites with carbon fibres were evaluated as better current conductors than the composites with metal fibres. By means of various kinds of carbon particles and fibres it is possible to design cement composites with an ability to monitor changes in electrical conductivity of concretes. The designed composites are assembled with conductive wires and connected with a special electronic equipment for monitoring of changes in alternate voltage passing through the tensometer within mechanical loading of a concrete element in which the composite is integrated. The tensometers are placed preferably into parts of the concrete elements subjected to compression, such as simple reinforced columns or upper parts of longitudinal beams. Several tests of repeated loading and simultaneous monitoring of vertical as well as horizontal prefabricated concrete elements were carried out and evaluated.
\end{abstract}

\section{Introduction}

Nowadays, characteristics of composite materials based on cement include also other applications, among others for construction of self-monitoring buildings, bridges, etc. Besides monitoring the usual properties (mechanical stability over the period of time, environmental resistance, design limits or economic profitability) it becomes to be more important and significant for construction of buildings.

One of the most common structural materials used in engineering construction is cement and its mixtures (concrete and mortar). Cement is slightly conducting material, but its electrical conductance, Electro-magnetic interference (EMI) shielding effectiveness and wave absorbing properties are very poor. In order to increase the ability of cement materials to transfer electrons, additional conductive components have to be added.

The strain-sensing properties are achieved by a proper volume amount of conductive filler. In this system, the matrix is made of cementitious material with small amount of silica fume, fly ash, and fine aggregates [1].

Different conductive fillers were tested considering the best strain-sensitivity/material price ratio. The best strain-sensitivity is achieved near the percolation threshold of filler particles [2].
Strain properties of the composite can be evaluated by impedance changing. The impedance changing sensitivity regarding deformation can be widely affected by a proper choice of concrete admixtures [3]. The real part of impedance is strongly affected by deformation and can be used for measurements.

Conventional DC techniques for resistance measurements cannot be used. Electrode system of a sensing element could be damaged by electrolytic corrosion in this case. Square-wave AC technique with an excitation frequency of $1 \mathrm{kHz}$ and an excitation voltage of $1 \mathrm{~V}$ were experimentally set [3].

As carbon particles there were used expanded or micronized graphite, fibres were on the base of polyacrylonitrile (PAN) or pitch. The optimal variants were used for preparation of one-dimensional specimens most suitable for measurement of simplified impact of stress and strain.

\section{Materials and methods}

\subsection{Carbon materials for concrete conductivity improvement}


In the course of searching for suitable components there were selected mainly various kinds of micronized or expanded graphite with particle size in micro- or nanometers, which is characterized by excellent electrical properties as well as good compatibility with a cement matrix, except for higher demand of batch water due to its bulk specific surface.

Carbon black with similar properties as micronized graphite was used as well. Carbon black has elementary particles generally in a range from 10 to 100 nanometers, but during the production process individual spherical particles agglomerate in chains or clusters. Micronized graphite has carbon content above $80 \%$; carbon black has high carbon content $(99 \%)$. Expanded graphites have lower carbon content $(60-96 \%)$.

Considering an application based on a relation between electrical behavior and mechanical strain and reverse deformation of concrete elements, two types of fibre reinforcement (carbon and metal) were chosen.

\subsection{Composite mixtures with carbon particles and fibres}

All mixtures were prepared in a mixer with a stationary drum and forced movement of paddles. Standard finegrained matrix consisting of cement, sand and fine filler with $3 \%$ of dry mixture weight reinforcement by alkaliresistant glass fibres with length $12 \mathrm{~mm}$ was chosen for further modifications.

The addition of carbon particles induces good electrical properties in cement-based composites. Though carbon fibres are less conductive than metal fibres, composites with carbon fibres were evaluated as better current conductors than the composites with metal fibres. It is supposed that this is due to extremely fine size of carbon fibres which provides more effective inter-fibre continuity. Therefore, further research was carried out with carbon particles and carbon fibres.

During the tests suitability of fine-grained particle and fibre combination was confirmed. The proportion of carbon particles was expressed as a percentage of a dry mixture weight (cement + sand + fine filler) as a substitution of a part of sand in range of $4-10 \%$ per weight. Carbon fibres with diameter $18 \mu \mathrm{m}$ and length $10 \mathrm{~mm}$ substituted for glass fibres up to $2 \%$ per weight. Basic components stated in Table 1 are as follows: carbon fibre $\mathrm{CF}$, micronized graphite $\mathrm{MG}$, expanded graphite EG and nickel-coated expanded graphite EG/Ni.

Table 1. Basic mixture compositions.

\begin{tabular}{|c|c|c|c|c|}
\hline Mixture components & CF & MG & EG & EG/Ni \\
\hline Cement binder & $54 \%$ & $54 \%$ & $54 \%$ & $54 \%$ \\
\hline Silica filler & $40 \%$ & $34 \%$ & $36 \%$ & $35 \%$ \\
\hline
\end{tabular}

\begin{tabular}{|c|c|c|c|c|}
\hline Fine filler & $3 \%$ & $3 \%$ & $3 \%$ & $3 \%$ \\
\hline Glass fibre & $1 \%$ & $1 \%$ & $1 \%$ & $1 \%$ \\
\hline Carbon fibre & $2 \%$ & $2 \%$ & $2 \%$ & $2 \%$ \\
\hline Micronized graphite & - & $6 \%$ & - & $3 \%$ \\
\hline Expanded graphite & - & - & $4 \%$ & - \\
\hline Nickel-coated graphite & - & - & - & $2 \%$ \\
\hline
\end{tabular}

\subsection{Influence on workability}

Fibre-cement mixtures were prepared in order to achieve optimal workability and minimal impedance, i.e. maximal electrical conductivity. To compare an influence of the type of carbon matter on impedance of the cement-fibre composite, each carbon powder always replaced the same proportion of dry components.

Carbon origin as well as particle size both affect impedance properties of the final composites, and as well the particle size affects workability of fresh mixtures. It was found that the finer carbon powder, the lower was the impedance and the worse mixture workability. Carbon particles should be properly dispersed among other mixture components without bleeding during transport and molding. With carbon fibres the perfect defibering and ideal anchoring in binder should be reached [4].

\subsection{Mixture optimization}

Within the optimization process fine fillers were withdrawn from the composition. Despite the positive effect on dense structure and better mechanical characteristics of composites, pozzolanic admixtures increase electric resistance of concrete mixtures [5].

All specimens were cured in laboratory conditions close to real manufacture conditions with temperature $25^{\circ} \mathrm{C}$ and humidity $55 \%$. The physical-mechanical properties of composites were tested on standard specimens for thin-walled fibre-cement elements with dimensions $250 \mathrm{~mm} \times 50 \mathrm{~mm} \times 10 \mathrm{~mm}$ at 28 days.

Higher water/cement ratio causes significantly higher absorption and lower bulk density, associated with low flexural strength and impact strength of the final composites.

\subsection{Measurement of electrical properties}

Ions in pore solutions cause conducting of electric current in concretes. Conduction of electrical current in cements 
and concretes is essentially electrolytic. In order to avoid problems of polarization, alternate currents are often used for determining resistivity of electrolytes and therefore also of cements and concretes [6].

Percolation threshold expresses minimal concentration of the certain component that creates the first conductive way through the whole volume of measured composite [4]. In the end percolation threshold of carbon fibres was determined to $0.75 \%$ of the dry mixture weight.

\section{Application of proposed elements}

\subsection{Electro-magnetic shielding}

Standard glass fibre reinforced concrete inhibits electromagnetic field up to approximately $-5 \mathrm{~dB}$ but our modified fibre-cement composite is able to achieve a level up to $-35 \mathrm{~dB}$. In comparison to a massive steel reinforced concrete the same shielding effect is achieved with using of incomparably less structural thickness.

In order to approach real conditions as much as possible the measurement was carried out in a special electro-magnetic chamber. Shielding efficiency was proven by the non-availability of any communication network inside the chamber [7]. A modified fibre-cement mixture was used for manufacturing of a concrete channel to demonstrate the application of electromagnetic shielding. It contains three chambers to separate electric cables with different voltage so that they do not interfere with each other.

\subsection{Concrete heating}

A fibre-cement slab with dimensions $1,800 \times 1,400 \mathrm{~mm}$, thickness $20 \mathrm{~mm}$ and circle openings with diameter $110 \mathrm{~mm}$ for better incorporation into a concrete panel was cast with the designed composition. An initial setting of openings in square lattice caused heating to occur only in stripes and not across the whole surface, therefore an optimization had to be done. After thermo-camera monitoring an orthorhombic setting of openings was evaluated as the most suitable for uniform heating ability.

A trafficable steel reinforced concrete panel was made with the ability to thaw snow cover or to defrost ice for reduction of slipping hazard on pavements or access ramps. The proposed element combines advantages of the solid bearing steel reinforced concrete and those of a thin fibre-cement slab with the required heating capacity.

\section{Monitoring of concrete structures}

It was concluded that cement composites with carbon fibres are suitable for monitoring of transition actions caused by change of strain, stress, temperature or humidity. Electrical resistance monitoring is a good way for characterization of cracks in concrete structure [8]. Besides ceiling panels, columns or foundations these elements could be implemented into the overloaded parts of bridge constructions.

Within experimental tests on flexural strength selected specimens with effective carbon addition provided measurable changes in the impedance. For the purpose of monitoring in conditions close to a real application a model of steel reinforced concrete structure was made. The model was used for evaluation of electrical properties of the embedded element as well as an influence of a concrete mass on these properties.

\subsection{Description of the measuring device}

The device function is based on 16-bit microcontroller and it is equipped with the Secure Digital (SD) card, which can be inserted into a side slot, for saving the measured data. SD card communicates with the microcontroller via Serial Peripheral Interface (SPI). A special feature of used microcontroller is built in Universal Serial Bus (USB) interface connection for transferring the measured data into PC. Microcontroller contains complete physical layer of USB communication device. Specialized software is able to receive this data and display it in a graph.

Under cover, there is a very well readable display panel. Four control buttons are placed from the front. The opposite side is equipped with eight connectors for measuring probes and four connectors for digital sensors. On the left side, there is the main switch and a connector for charging. The right side includes a water and dust proof USB connector with a rubber plug [9].

\subsection{Selection of the proper composition for conductive composites}

The aim was to design a cement-based composite with the ability to change its electrical properties in dependence on mechanical stress and strain by means of modified cement matrix. For this purpose, there was a search for suitable inorganic additives. 25 carbon materials of different origin were tested, including micromilled graphites, expanded graphites or high conductive carbon black. For the selected set of carbon particles an optimization process was carried out to reach the percolation threshold, i.e. the proper amount of an additive, for which no significant changes of electrical properties do not take place in the final composite.

Concerning results gathered within static as well as dynamic measurements, the most suitable additives carbon black and carbon fibres and their dosing were selected. The final composition consists of $50-60 \%$ of high-valuable cement, $30-45 \%$ of fine aggregate, up to $10 \%$ of carbon particles and up to $2 \%$ of carbon fibres.

\subsection{Testing of modified elements}

Planar elements were evaluated as inconvenient for monitoring of electrical response in individual directions of building elements for the reason of combined impact of stress and strain. Therefore, the elements were designed in the shape of prisms with one dominant 
dimension comparing to others to avoid multiparametrical loading effect. These specimens were made in two dimensions $40 \mathrm{~mm}$ x $40 \mathrm{~mm}$ x $160 \mathrm{~mm}$ or $20 \mathrm{~mm}$ x $20 \mathrm{~mm}$ x $100 \mathrm{~mm}$. In one set, there was 1 element with 2 copper contacts ca. $2-5 \mathrm{~mm}$ from the end as shown in figure 1 . The other 2 elements were intended for testing of physical-mechanical characteristics, i.e. compressive, flexural and tensile strength, bulk density and water absorptivity.

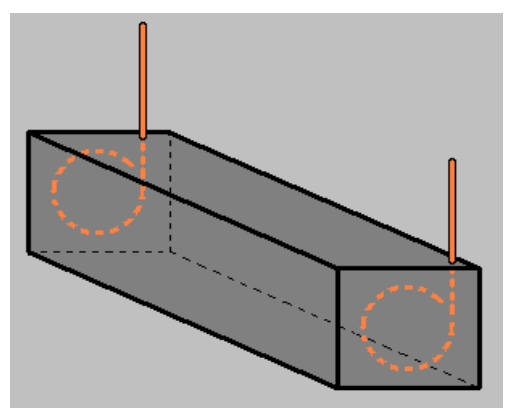

Fig. 1. Design of a modified element.

Cement-based tensometers are prepared from fresh mixture containing all the particular components listed above in accordance with required technological process. The mixture is filled into molds, copper contacts are inserted into it and an isolated part sticks out of it. After 28 days of curing in water the isolation is taken out and the tensometers are provided with long electrical outlets for connection to the measuring device. The tensometers were placed into molds for reinforced structural elements by means of electrically nonconducting straps according to the assembly drawing.

Impedance measurement of individual elements was conducted under following conditions: alternate voltage $1 \mathrm{~V}$ and frequency $1 \mathrm{kHz}$ were set to avoid corrosion of used copper electrodes. Maximal loading $1 \mathrm{kN}$ was set within the measurements to avoid unexpected damage of elements.

\subsection{Design of a concrete column}

Relation of deformation to impedance of composite elements has been already verified [6]. The next logical step was evaluation of this relation in the practical utilization. For evaluation of utilization of integrated composite elements in concrete or reinforced concrete column a model in standard cross section was designed. The final dimensions were $300 \mathrm{~mm}$ x $300 \mathrm{~mm}$ x $500 \mathrm{~mm}$. There were 2 variants - the first column without steel reinforcement and the second one with steel reinforcement for comparison.
In both variants 3 composite elements were put into the model column. The first one was placed vertically in the column centroid, the second one was placed horizontally above the first one and the third one was placed again vertically at the side of the column next to steel reinforcement. The similar placement was used for the variant without reinforcement. The aim was to compare effect of the steel reinforcement and a different position of individual composite elements.

A mold from water-proof plywood was made according to common praxis of the column production in the horizontal position. The composite elements were fixed in the mold by means of plastic strips to distance elements for the steel reinforcement (see figure 2). The concrete models were made from concrete C30/37 XC4 S4 D22 compacted by inner vibrators.

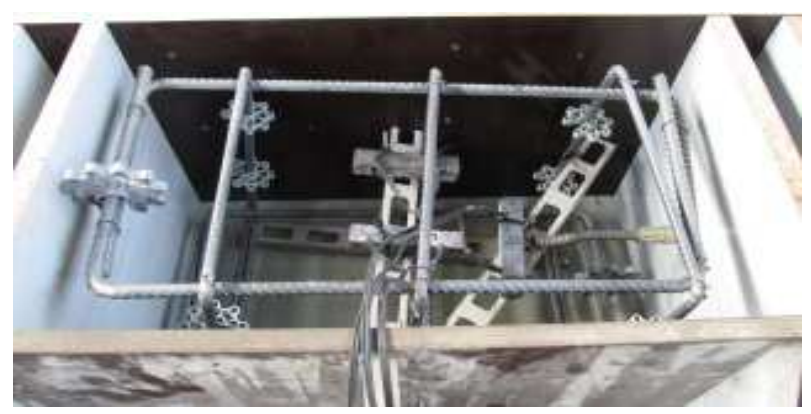

Fig. 2. Mold with the composite elements and steel reinforcement.

\subsection{Measurement of impedance and deformation during loading}

Model columns were supplemented by plugs for deformation measurement. Digital deviation indicators were fixed to the plugs [10]. Digital impedance detectors with generated alternate voltage of $1 \mathrm{~V}$ were fixed to cable outlets of the composite elements.

Loading of the model columns was simulated by means of the hydraulic press machine. Applied force reached values of 0 to $1,500 \mathrm{kN}$, which corresponds with pressure 16.7 MPa. Impedance of the composite elements and strain in the model columns was monitored in the course of loading in time of reaching $200 \mathrm{kN}$ (2.2 MPa) by hand operation and $5 \mathrm{x} 1,500 \mathrm{kN}$ $(16.7 \mathrm{MPa})$ in automatic mode and again de-loading to $200 \mathrm{kN}$.

In the achieved graphs, it is possible to see clear impedance change of the composite elements corresponding with changes of unit strain in the model columns as it is depicted in figure 3 . 


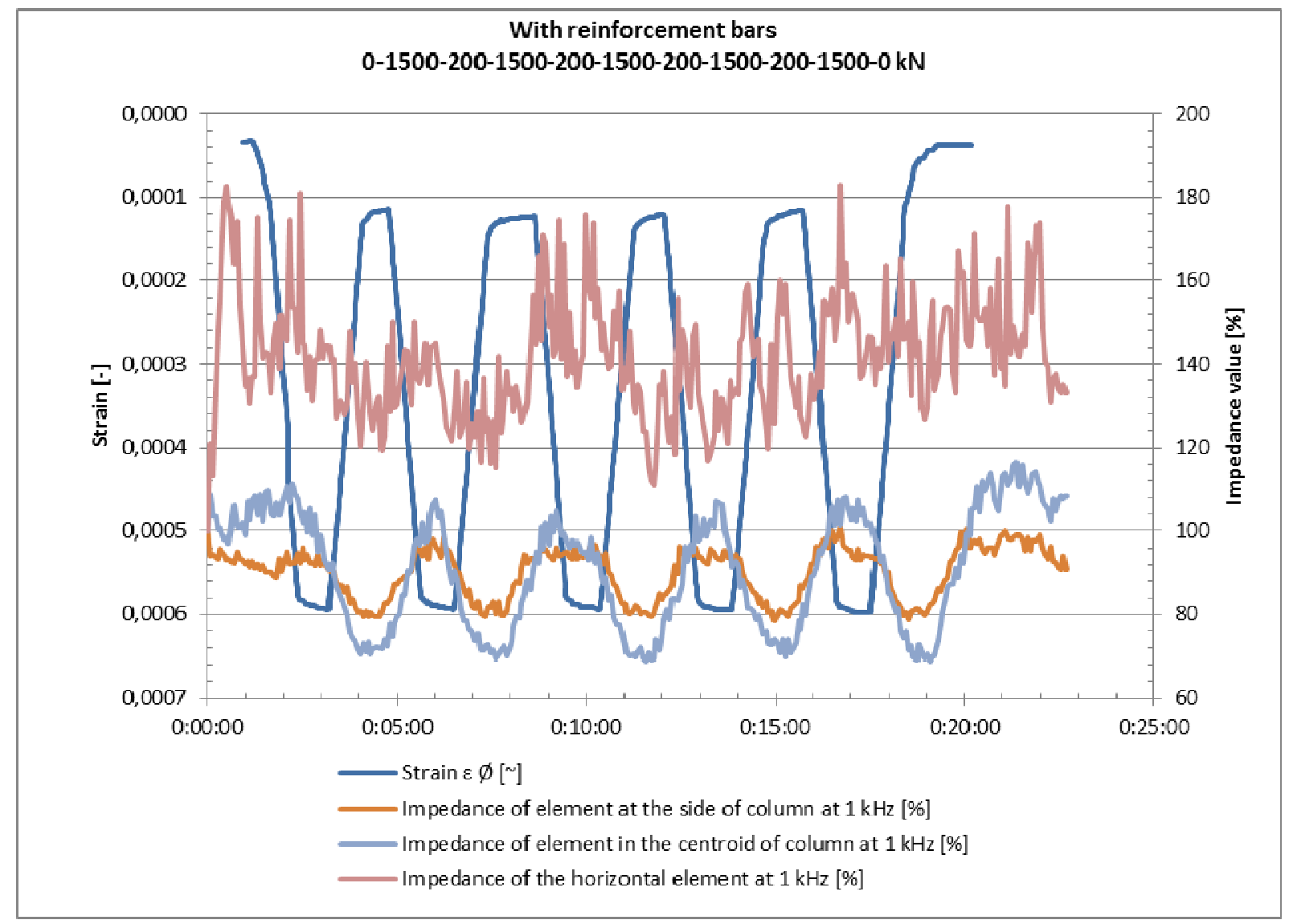

Fig. 3. Graph of strain and impedance in the course of loading for the reinforced column.

The subsequent measurement of relation of mechanical loading of a horizontal element and electrical properties of the composite tensometers was carried out in the specialized testing room without negative effects of the environment (effect of temperature and humidity). The element with dimensions $150 \times 150 \times 3,400 \mathrm{~mm}$ was subjected to 4point bending. The course of cyclical increase and decrease of the force $\mathrm{F}=0-50 \mathrm{kN}$, the induced deflection and the values of impedance during measurement were depicted again in graphs.

The impedance of tensometers was significantly changed in the case of overloading, when an accumulation of microcracks occurred on the tested element. This state we can describe as the emergency state of the structural elements, when it is necessary to send signal for evacuation of the building.

\section{Conclusion}

It was concluded that special fibre-cement composites are able to conduct electric current under specific conditions. This property is ensured by using of various kinds of carbon materials in a form of dispersive particles or fibres. Electric conductivity is monitored by means of impedance measurement of the designed elements. These composites could be used for heating of trafficable surfaces or shielding of electro-magnetic fields.
It is also possible to monitor internal processes in building structures and prevent them from collapsing. For this application it is necessary to design onedimensional elements to simplify the combined loading in the structures. Relation of impedance of the composite elements to unit strain in the model columns was successfully verified thereof. Positions of the composite elements in the models did not significantly affect monitored changes in impedance. It connected only to the absolute change of impedance, but not to the sensitivity to change detection. The ability to transform unit strain to change in impedance seemed to be a material parameter independent on shape and orientation of the composite elements.

\section{Acknowledgement}

The research was conducted under the project FRTI3/485 Engineering structure state monitoring by means of electrically conductive elements with modified cement matrix supported by the Ministry of Industry and Trade of the Czech Republic.

\section{References}

1. N. Xie et al, Percolation backbone structure analysis in electrically conductive carbon fiber reinforced cement composites, Composites Part B: Engineering 43 (2012), 3270-3275, ISSN 1359-8368 
2. H. Li et al, Effect of compressive strain on electrical resistivity of carbon black-filled cement-based composites, Cement and Concrete Composites 28, Issue 9 (2006), 824828, ISSN 0958-9465

3. R. Cechmanek et al, Carbon-Based Composites Enable Monitoring of Internal States in Concrete Structures, International Journal of Civil, Structural, Construction and Architectural Engineering 8, No.10, Part I (2014), 70-75, elSSN 1307-6892

4. F. Vossoughi, Electrical resistivity of carbon fiber reinforced concrete, CE241: Concrete Technology (University of California, Berkeley, 2004)

5. P. Hosseini, M. Moradian, Performance of pozzolanic admixtures on mechanical and durability properties of concrete, Proceedings of Microstructural-related Durability of Cementitious Composites, 656664, ISBN 978-2-35158-129-2, Amsterdam, April 2012 (RILEM, Amsterdam, 2012)

6. P. Nikkanen, On the Electrical Properties of Concrete and Their Application (Valtion Teknillinen Tiedotus, Rakennus, 1962)

7. P. Šteffan et al, A New Measuring Method Suitable for Measuring Shielding Efficiency of Composite Materials with Carbon Fibers, Proceedings of 2010 Fifth International Conference on Systems, 186-189, ISBN 9780-7695-3980-5, Menuires, April 2010 (IEEE Computer Society Digital Library, 2010), Available from http://www.computer.org/portal/ web/csdl/doi/10.1109/ICONS.2010.39

8. J. Pacheco et al, Relationship between cracking and electrical resistance in reinforced and unreinforced concrete, Proceedings of Microstructural-related Durability of Cementitious Composites, 458-466, ISBN 9782-35158-129-2, Amsterdam, April 2012, (RILEM, Amsterdam, 2012)

9. L. Macháñ, P. Šteffan, A New Laboratory Equipment for Characterization of Smart Concrete Materials, Proceedings of ICONS 2013 The Eighth International Conference on Systems, 123-126, ISBN 978-1-61208-246-2, Seville, January/February 2013 (IARIA XP S Press, Seville, 2013)

10. J. Malikova, Test protocol No. 060-038, Technical and test institute for construction Prague, Brno (2013) 